\title{
BMJ Open Mental health among Ebola survivors in Liberia, Sierra Leone and Guinea: results from a cross-sectional study
}

\author{
Andrew Secor (10 , ${ }^{1,2}$ Rose Macauley, ${ }^{1}$ Laurentiu Stan, ${ }^{3}$ Meba Kagone, ${ }^{4}$ \\ Sidibe Sidikiba, ${ }^{4}$ Sadou Sow, ${ }^{4}$ Dana Aronovich, ${ }^{5}$ Kate Litvin, ${ }^{5}$ Nikki Davis, ${ }^{5}$ \\ Soumya Alva, ${ }^{5}$ Jeff Sanderson ${ }^{5}$
}

To cite: Secor A, Macauley R, Stan L, et al. Mental health among Ebola survivors in Liberia, Sierra Leone and Guinea: results from a crosssectional study. BMJ Open 2020;10:e035217. doi:10.1136/ bmjopen-2019-035217

- Prepublication history for this paper is available online. To view these files, please visit the journal online (http://dx.doi. org/10.1136/bmjopen-2019035217).

Received 23 0ctober 2019 Revised 21 March 2020 Accepted 15 April 2020

Check for updates

C Author(s) (or their employer(s)) 2020. Re-use permitted under CC BY-NC. No commercial re-use. See rights and permissions. Published by BMJ.

${ }^{1} \mathrm{JSI}$ Research and Training Institute Inc, Monrovia, Liberia ${ }^{2}$ Department of Global Health, University of Washington, Seattle, Washington, USA

${ }^{3} \mathrm{JSI}$ Research and Training Institute Inc, Freetown, Sierra Leone

${ }^{4} \mathrm{JSI}$ Research and Training Institute Inc, Conakry, Guinea

${ }^{5} \mathrm{JSI}$ Research and Training Institute Inc, Arlington, Virginia, USA

Correspondence to

Mr Andrew Secor;

amsecor@gmail.com

\section{ABSTRACT}

Objectives To describe the prevalence and correlates of depression and anxiety among adult Ebola virus disease (EVD) survivors in Liberia, Sierra Leone and Guinea.

Design Cross-sectional.

Setting One-on-one surveys were conducted in EVDaffected communities in Liberia, Sierra Leone and Guinea in early 2018.

Participants 1495 adult EVD survivors (726 male, 769 female).

Primary and secondary outcome measures Patient Health Questionnaire-9 (PHQ-9) depression scores and Generalised Anxiety Disorder-7 (GAD-7) scores.

Results Prevalence and severity of depression and anxiety varied across the three countries. Sierra Leone had the highest prevalence of depression, with $22.0 \%$ of participants meeting the criteria for a tentative diagnosis of depression, compared with $20.2 \%$ in Liberia and $13.0 \%$ in Guinea. Sierra Leone also showed the highest prevalence of anxiety, with $10.7 \%$ of participants meeting criteria for generalized anxiety disorder (GAD-7 score $\geq 10$ ), compared with $9.9 \%$ in Liberia and $4.2 \%$ in Guinea. Between one-third and one-half of respondents reported little interest or pleasure in doing things in the previous 2 weeks (range: $47.0 \%$ in Liberia to $37.6 \%$ in Sierra Leone), and more than 1 in 10 respondents reported ideation of self-harm or suicide (range: $19.4 \%$ in Sierra Leone to $10.4 \%$ in Guinea). Higher depression and anxiety scores were statistically significantly associated with each other and with experiences of health facility-based stigma in all three countries. Other associations between mental health scores and respondent characteristics varied across countries.

Conclusions Our results indicate that both depression and anxiety are common among EVD survivors in Liberia, Sierra Leone and Guinea, but that there is country-level heterogeneity in prevalence, severity and correlates of these conditions. All three countries should work to make mental health services available for survivors, and governments and organisations should consider the intersection between EVD-related stigma and mental health when designing programmes and training healthcare providers.

\section{Strengths and limitations of this study}

- Depression and anxiety were evaluated using well validated, widely used tools (the Patient Health Questionnaire-9 and Generalised Anxiety Disorder-7 questionnaires), standardising assessment across the three countries and allowing for comparison to other studies using the same tools.

Where possible, Ebola virus disease (EVD) survivors acted as enumerators, hopefully reducing response bias associated with EVD-related stigma.

- Due to use of survivor registries for sampling, our sample is likely biased towards survivors who are connected with advocacy groups and healthcare services.

- This was a cross-sectional study, precluding causal inference between mental health and covariates of interest.

\section{INTRODUCTION}

During the unprecedented 2014-2016 Ebola outbreak, Liberia, Sierra Leone and Guinea experienced more than 28000 cases of Ebola virus disease (EVD), leaving an estimated

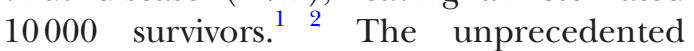
number of survivors has raised questions about long-term health complications of EVD survivorship and the capacity of local health systems to meet these needs.

Prior and emerging research has shown EVD survivorship to be associated with myriad sequelae, including musculoskeletal pain, ocular conditions and mental health issues. ${ }^{3-7}$ Recent studies from the West Africa outbreak have found that many survivors suffer from symptoms associated with mental health conditions. ${ }^{38-13}$ A 2015 study among EVD survivors in Sierra Leone found that $48 \%$ showed symptoms of anxiety or depression, and $76 \%$ showed symptoms of post-traumatic stress disorder (PTSD). ${ }^{8}$ In Guinea, $15 \%$ of survivors met criteria for psychological suffering, ${ }^{3}$ and in Liberia $13 \%$ 
of survivors presented with symptoms of depression and/ or anxiety. ${ }^{9}$

The impacts of EVD infection are far-reaching. In addition to health complications, many survivors also experienced loss of friends and family, as well as stigmatisation and ostracisation in their communities and at health facilities, leading to further degradation of traditional social support structures and the ability or willingness to engage with care. ${ }^{1415}$ One study in Sierra Leone found that $67 \%$ of survivors had witnessed the death of a family member to EVD, and $32 \%$ experienced stigma in their communities after returning home from the Ebola treatment unit. ${ }^{10}$ These experiences and issues can have long-term impact on the survivors' well-being and the ability of the health system to respond to their health needs.

The aims of this study are to describe the prevalence and correlates of depression and anxiety among adult EVD survivors in Liberia, Sierra Leone and Guinea, in order to better understand the health needs of this population and to inform further health programmes and policies. This research is particularly salient considering the current Ebola outbreak in the Democratic Republic of Congo.

\section{METHODS}

\section{Design and sample}

This was a cross-sectional survey conducted in USAID EVD-priority regions in Liberia, Sierra Leone and Guinea as part of the Ebola Transmission Prevention \& Survivor Services (ETP\&SS) programme, a USAID-funded, EVDsurvivor focused programme implemented between 2016 and 2018. Data collection was conducted in early 2018. The final sample size was 1495 (Guinea $=531$, Liberia $=213$, Sierra Leone $=751$ ). Randomised samples stratified by administrative region and sex were drawn from survivor registries in each country. Representatives from local survivor associations played an essential role in facilitating the research by contacting and mobilising participants. Inclusion criteria were: verified EVD survivor status and age 18 or over. Data collectors received 3-7 days of training (depending on the country), which included review of ethics and confidentiality practices. Mobile phones or tablets were used for data collection, and all surveys were conducted in-person.

\section{Measures}

Patient Health Questionnaire-9

The Patient Health Questionnaire-9 (PHQ-9) is a selfadministered depression screening tool based on the nine Diagnostic and Statistical Manual of Mental Disorders (DSM-5) criteria for major depressive disorder. ${ }^{16}{ }^{17}$ It has been validated in several sub-Saharan African countries and with a number of stigmatised and vulnerable populations. ${ }^{18-20}$ Questions ask about experience of each criterion in the past 2 weeks and are scored on a 4-point Likert scale of frequency (eg, 'more than half the days'), with an overall range of 0 to 27. The score can be interpreted using a diagnostic algorithm to generate a tentative diagnosis of major depressive disorder or other depressive disorder, as a continuous summary score, or as a severity scale. ${ }^{17}$ In this study, the PHQ-9 had a Cronbach's alpha of 0.82 , suggesting high internal reliability.

\section{Generalised Anxiety Disorder-7}

Similar to the PHQ-9, the Generalised Anxiety Disorder-7 (GAD-7) is a self-administered screening tool based on the seven DSM criteria for GAD and has been validated in several sub-Saharan African countries and among vulnerable populations. ${ }^{21}$ Questions ask about experience of each criterion in the past 2 weeks and are scored on a 4-point Likert scale of frequency (eg, 'more than half the days'), with an overall range of 0 to 21. The score can be interpreted using a validated cut-point of 10 for a tentative diagnosis of GAD or as a continuous summary score. ${ }^{22}$ In this study, the GAD-7 had a Cronbach's alpha of 0.83 , suggesting high internal reliability.

\section{Stigma}

Liberia and Guinea used the same stigma questions while Sierra Leone used a modified questionnaire. The Liberia and Guinea surveys asked about experience of five types of stigma at a health facility in the last year: refusal of service due to survivor status, longer wait times for services than non-survivors, receiving less care or attention than non-survivors, providers gossiping about survivor status, and providers being nervous to treat them due to their survivor status. Additionally, participants were asked if they had avoided or delayed seeking care due to fear of stigma. The Sierra Leone survey included four questions on health facility-based stigma and five questions on community-based stigma, including questions on disclosure of EVD status (health facility), denial of health services (health facility), verbal insult (community) and physical assault (community). Stigma was analysed as continuous scores disaggregated by setting (community vs health facility). Cronbach's alphas ranged from 0.45 (Guinea, health facility) to 0.75 (Sierra Leone, community) by country and setting, suggesting moderate to low internal reliability and moderate to high heterogeneity in types of stigma experienced.

\section{Patient and public involvement}

Patients and the general public were not directly involved in the design of the research or analysis of the data. To decrease the likelihood of response bias, and where possible, Ebola survivors acted as data collectors and survivor advocacy bodies facilitated participant location and communication.

Written or verbal consent was obtained from all participants.

Further, to ensure that respondents exhibiting signs of anxiety and/or depression during the survey accessed services, mechanisms were established to facilitate referral and/or follow-up by mental health providers. Participants with high scores on either the PHQ-9 or GAD-7 
Table 1 Respondent characteristics and stigma experience

\begin{tabular}{cccc}
\hline & \multicolumn{3}{c}{$\mathbf{N}(\%)$ or med (IQR) } \\
\cline { 2 - 4 } Indicator & $\begin{array}{l}\text { Liberia } \\
(\mathbf{n}=\mathbf{2 1 3})\end{array}$ & $\begin{array}{l}\text { Sierra Leone } \\
(\mathbf{n}=\mathbf{7 5 1})\end{array}$ & $\begin{array}{l}\text { Guinea } \\
(\mathbf{n}=531)\end{array}$ \\
\hline Age & & & \\
\hline $18-24$ & $37(17.4)$ & $129(17.2)$ & $126(23.8)$ \\
\hline $25-34$ & $69(32.4)$ & $284(37.8)$ & $148(27.9)$ \\
$35-44$ & $55(25.8)$ & $199(26.5)$ & $125(23.6)$ \\
$45-54$ & $31(14.6)$ & $88(11.7)$ & $70(13.2)$ \\
$55-64$ & $18(8.5)$ & $40(5.3)$ & $38(7.2)$ \\
$65+$ & $8(1.4)$ & $11(1.5)$ & $23(4.3)$ \\
\hline
\end{tabular}

Sex

\begin{tabular}{|cccc|}
\hline Male & $90(42.3)$ & $377(50.2)$ & $259(48.8)$ \\
\hline Female & $123(57.8)$ & $374(49.8)$ & $272(51.2)$ \\
\hline Education & & & \\
\hline None & $61(28.6)$ & $381(50.7)$ & $259(48.8)$ \\
\hline Primary & $41(19.3)$ & $46(6.1)$ & $79(14.9)$ \\
\hline Secondary & $97(45.5)$ & $271(36.1)$ & $117(22.0)$ \\
Vocational & $3(1.4)$ & $39(5.2)$ & $25(4.7)$ \\
University & $11(5.2)$ & $14(1.9)$ & $51(9.6)$ \\
Married (yes) & $60(33.5)$ & $387(51.5)$ & $330(72.1)$ \\
\hline Religion & & & \\
Christian & $165(77.5)$ & No data & $415(78.2)$ \\
Muslim & $48(22.5)$ & & $101(19.0)$ \\
Other & No data & & $15(2.8)$ \\
\hline
\end{tabular}

Stigma $(1+$

experience)

\begin{tabular}{llll}
$\begin{array}{l}\text { Community } \\
\text { based }\end{array}$ & No data & $374(54.8)$ & No data \\
$\begin{array}{l}\text { Facility based } \\
\text { 58(27.2) }\end{array}$ & 125(19.5) & 168(35.1) \\
\hline
\end{tabular}

were provided with contact information for a mental health focal nurse in their area. For those with severe scores or self-reported suicidal or self-harm ideation in the previous 2 weeks, data collectors made direct contact with the mental health focal nurse to initiate a referral with the respondent's consent.

\section{Data analysis}

Data were analysed using Stata V.13. Descriptive statistics were analysed using means and SD or medians and IQRs depending on variable type and distribution. Differences between outcomes by country were assessed using analysis of variance (ANOVA). Associations between mental health scores and covariates of interest (age, sex, education, religion, marriage status, being a health worker during the outbreak, stigma and awareness of survivor advocacy groups) were assessed using $\mathrm{X}^{2}$ tests and univariable linear regression with robust SEs.
RESULTS

Table 1 summarises descriptive statistics of the study population. In total, 1495 survivors were included in the study $($ Libera $=213$, Sierra Leone $=751$, Guinea $=531)$. The majority $(78.5 \%)$ of respondents were aged $18-44$, female $(51.4 \%)$, married $(56.0 \%)$ and reported being the head of household $(62.9 \%)$. Roughly half $(53.1 \%)$ of respondents reported having some formal education, with $32.4 \%$ having secondary school as their highest educational achievement.

Thirty-five per cent $(35.1 \%)$ of respondents in Guinea reported experiencing at least one occurrence of EVD-related stigma at a health facility in the last year, compared with $27.2 \%$ in Liberia and $19.5 \%$ in Sierra Leone. Roughly 1 in 10 survivors in Liberia and Guinea reported avoiding care due to this stigma (10.3\% and $9.3 \%$, respectively, equivalent data not collected in Sierra Leone). In Sierra Leone, $54.8 \%$ of respondents reported experiencing at least one occurrence of EVD-related stigma in the community (equivalent data not collected in Liberia and Guinea).

As stipulated in the informed consent process, participants were allowed to skip any survey questions they did not feel comfortable answering, including the PHQ-9 or GAD-7. Seventeen participants did not complete the PHQ-9 (15 in Liberia and 2 in Guinea), and 12 did not complete the GAD-7 (10 in Liberia and 2 in Guinea). As total scores are used to assess depression and anxiety prevalence and severity, incomplete questionnaires were discarded from the analysis (Liberia=15, Guinea=2 and no missing scores in Sierra Leone).

Table 2 presents country-specific summary statistics for the mental health questionnaires. ANOVA and $\mathrm{X}^{2}$ tests showed statistically significant differences between the countries for both depression and anxiety scores, and for all covariates except sex. As such, results are reported disaggregated by country.

Sierra Leone had the highest prevalence of depression, with $22.0 \%$ of participants meeting the criteria for a tentative diagnosis of depression, compared with $20.2 \%$ in Liberia and $13.0 \%$ in Guinea. The PHQ-9 allows for disaggregation by type of depressive disorder, and $7.1 \%$, $6.8 \%$, and $3.6 \%$ met the criteria for major depressive disorder (also known as clinical depression) in Sierra Leone, Liberia and Guinea, respectively.

Sierra Leone also showed the highest prevalence of anxiety, with $10.7 \%$ of participants meeting criteria for generalized anxiety disorder (GAD-7 score $\geq 10$ ), compared with $9.9 \%$ in Liberia and $4.2 \%$ in Guinea. Additionally, $7.3 \%$ of respondents in Sierra Leone had comorbid anxiety and depression, compared with $5.6 \%$ in Liberia, and $3.0 \%$ in Guinea.

Experience of individual depression and anxiety criterion also varied between the countries (see table 3). Across all three countries, between one-third and onehalf of respondents reported little interest or pleasure in doing things in the 2 weeks previous to the survey (range: $47.0 \%$ in Liberia to $37.6 \%$ in Sierra Leone); feeling down, 
Table 2 PHQ-9 and GAD-7 results

\begin{tabular}{|c|c|c|c|c|}
\hline \multirow[b]{2}{*}{ Indicator } & \multicolumn{3}{|c|}{ N (\%) or med (IQR) } & \multirow[b]{2}{*}{$\begin{array}{l}\text { Correlation statistic } \\
\text { (country comparison) }\end{array}$} \\
\hline & $\begin{array}{l}\text { Liberia } \\
(\mathrm{n}=213)\end{array}$ & $\begin{array}{l}\text { Sierra Leone } \\
(n=751)\end{array}$ & $\begin{array}{l}\text { Guinea } \\
(n=531)\end{array}$ & \\
\hline Depression (PHQ-9) & & & & Cronbach's alpha $=0.82$ \\
\hline PHQ-9 score (continuous) & $4(2-9)$ & $4(1-8)$ & $3(0-6)$ & $\begin{array}{l}\text { ANOVA }(F(2,1478)=20.2 \\
p<0.001)\end{array}$ \\
\hline PHQ-9 (severity scale) & & & & $X^{2}=38.3, p<0.001$ \\
\hline Mild (5-9) & $53(26.8)$ & $214(28.5)$ & 129(24.4) & \\
\hline Moderate (10-14) & $31(15.7)$ & 104(13.9) & $38(7.2)$ & \\
\hline Mod. severe (15-19) & $7(3.5)$ & 26(3.5) & $8(1.5)$ & \\
\hline Severe (20-27) & $5(2.5)$ & $6(0.8)$ & $3(0.6)$ & \\
\hline PHQ-9 (tentative diagnostic) & & & & $X^{2}=17.4, p=0.002$ \\
\hline GAD-7 score (continuous, range $=0-21$ ) & $3(1-6)$ & $4(0-7)$ & $2(0-4)$ & $\begin{array}{l}\text { ANOVA }(F(2,1484)=29.8 \\
p<0.001)\end{array}$ \\
\hline GAD-7 (severity scale) & & & & $X^{2}=64.5, p<0.001$ \\
\hline Minimal $(0-4)$ & 129(63.6) & $434(57.8)$ & $410(77.4)$ & \\
\hline Mild (5-9) & $54(26.6)$ & $237(31.6)$ & $98(18.5)$ & \\
\hline Moderate (10-14) & $12(5.9)$ & $69(9.2)$ & 19(3.6) & \\
\hline Severe (15-21) & $8(3.9)$ & $11(1.5)$ & $3(0.6)$ & \\
\hline GAD-7 (tentative diagnostic) & & & & $X^{2}=18.2, p<0.001$ \\
\hline GAD & 20(9.9) & $80(10.7)$ & $22(4.2)$ & \\
\hline
\end{tabular}

GAD-7, Generalised Anxiety Disorder-7; PHQ-9, Patient Health Questionnaire-9.

depressed or hopeless (range: $54.5 \%$ in Sierra Leone to $42.6 \%$ in Liberia); or not being able to stop or control worrying (range: $49.4 \%$ in Sierra Leone to $29.2 \%$ in Guinea). Of particular concern, in all three countries, more than 1 in 10 respondents reported ideation of selfharm or suicide (range: $19.4 \%$ in Sierra Leone to $10.4 \%$ in Guinea).

Tables 4 and 5 present country-specific univariable linear regressions between PHQ-9, GAD-7, sociodemographic characteristics and stigma. Analysed as continuous values, depression and anxiety scores showed moderate to strong association in all three countries: Liberia (beta $=0.85$, $\mathrm{p}<0.001$ ), Sierra Leone (beta $=0.86, \mathrm{p}<0.001$ ) and Guinea (beta $=0.96, \mathrm{p}<0.001$ ). Being female was associated with higher depression scores in both Sierra Leone (beta $=0.98$, $\mathrm{p}=0.004$ ) and Guinea (beta $=0.85, \mathrm{p}=0.02$ ), as well as with higher anxiety scores in Sierra Leone (beta $=0.79$, $\mathrm{p}=0.007$ ) and Guinea (beta $=0.61, \mathrm{p}=0.03$ ). Sex showed no association with either depression or anxiety in Liberia. Being a health worker during the outbreak was associated with lower anxiety scores in Liberia $(-1.76, \mathrm{p}=0.02)$, but no association was found with depression in Liberia or with either condition in Guinea (no equivalent data in Sierra Leone).

In Liberia, recent experience with health facility-based EVD-related stigma was associated with higher depression scores (beta $=1.39, \mathrm{p}<0.001)$, while anxiety scores were of marginal significance (beta $=0.54, \mathrm{p}=0.052$ ). Similar results were seen in Guinea for depression (beta $=0.97$, $\mathrm{p}=0.002$ ) and anxiety (beta $=0.38, \mathrm{p}=0.12$ ). In Sierra Leone, higher scores for both depression and anxiety were statistically significantly associated with facility-based stigma (beta $=2.02, \mathrm{p}<0.001$; beta $=1.87, \mathrm{p}<0.001$ ) and community-based stigma (beta $=0.29, \mathrm{p}=0.03$; beta $=0.48$, $\mathrm{p}<0.001)$. In Liberia, avoiding healthcare due to fear of stigma was associated with higher depression scores (beta=2.71, $\mathrm{p}=0.03$ ) and anxiety scores (beta $=1.60$, $\mathrm{p}=0.04)$. In Guinea, avoiding care showed significant association with higher depression scores (beta $=1.61, \mathrm{p}=0.02$ ) but not with anxiety scores (beta $=0.61, \mathrm{p}=0.27$ ).

Unexpectedly, in Sierra Leone, awareness of survivor advocacy groups was significantly associated with higher depression scores (beta $=2.98, \mathrm{p}<0.001$ ) and anxiety scores (beta $=2.10, p<0.001$ ). Awareness of these groups was associated with lower anxiety scores in Guinea (beta $=-0.78$, $\mathrm{p}=0.007$ ) and showed no significant association in Liberia.

\section{DISCUSSION}

Our investigation of the prevalence of mental health conditions among adult EVD survivors in West Africa revealed moderate levels of both depression and anxiety 
Table 3 PHQ-9 and GAD-7 item-specific responses

\begin{tabular}{|c|c|c|c|c|}
\hline \multicolumn{2}{|c|}{$\begin{array}{l}\text { Questionnaire item } \\
\text { (\% reporting any experience of in last } 2 \text { weeks) }\end{array}$} & \multirow{2}{*}{$\begin{array}{l}\text { Liberia } \\
47.0\end{array}$} & \multirow{2}{*}{$\begin{array}{l}\text { Sierra Leone } \\
37.6\end{array}$} & \multirow{2}{*}{$\begin{array}{l}\text { Guinea } \\
41.2\end{array}$} \\
\hline PHQ-9 & Little interest or pleasure in doing things & & & \\
\hline & Trouble falling or staying asleep, or sleeping too much & 46.7 & 45.9 & 38.0 \\
\hline & Feeling tired or having little energy & 57.7 & 66.2 & 52.2 \\
\hline & $\begin{array}{l}\text { Trouble concentrating on things, such as reading the newspaper or watching } \\
\text { television }\end{array}$ & 36.3 & 28.8 & 18.9 \\
\hline & $\begin{array}{l}\text { Moving or speaking so slowly that other people could have noticed. Or the } \\
\text { opposite being so fidgety or restless that you have been moving around a lot } \\
\text { more than usual }\end{array}$ & 26.9 & 24.8 & 14.3 \\
\hline & Not being able to stop or control worrying & 42.4 & 49.4 & 29.2 \\
\hline & Worrying too much about different things & 50.7 & 56.1 & 37.4 \\
\hline & Trouble relaxing & 36.0 & 35.3 & 23.7 \\
\hline & Being so restless that it's hard to sit still & 21.2 & 31.6 & 13.9 \\
\hline & Becoming easily annoyed or irritable & 44.3 & 46.7 & 27.9 \\
\hline & Feeling afraid as if something awful might happen & 28.1 & 29.6 & 18.6 \\
\hline
\end{tabular}

GAD-7, Generalised Anxiety Disorder-7; PHQ-9, Patient Health Questionnaire-9.

among survivors in Liberia, Sierra Leone and Guinea, with statistically significant differences across the countries for both conditions. Depression and anxiety were highest in Sierra Leone, although Liberia had a slightly higher proportion presenting with major depressive disorder. Survivors in Guinea presented with the lowest proportion of both depression and anxiety.

We found heterogeneity in associations between the mental health conditions and respondent characteristics between the countries. For example, women in Guinea and Sierra Leone showed higher depression and anxiety scores as compared with men, but no such relationship was found in Liberia. Awareness of survivor advocacy groups was associated with lower anxiety scores in Guinea but, unexpectedly, higher scores in Sierra Leone. This could be because survivors with greater health needs being more likely to connect with the advocacy groups, as the groups often acted as a facilitation point for medical care for survivors (eg, providing transportation to medical appointments). These findings suggest that there are varying contextual and environmental factors and drivers for the mental health conditions among survivors between countries.

The Global Burden of Disease estimates that approximately $4 \%-5 \%$ of the global population suffers from depression and $4 \%$ from GAD. ${ }^{23}$ A review of mental health prevalence research found that GAD prevalence in West Africa was estimated at between 2.8\% and 5.2\% ${ }^{24}$ However, due to the lack of robust, population-level data on mental health conditions in any of the study countries, this article cannot directly compare the conditions among EVD survivors to the general population. There is, however, an emerging research base on the burden of mental health issues among survivors in West Africa. Recent studies in Liberia and Guinea have found similar levels of depression among survivors as in this study. A 2018 retrospective cross-sectional study of patient records for survivor visits to a hospital in Monrovia, Liberia, found that $13 \%$ of survivors had symptoms of depression and $13 \%$ for anxiety. ${ }^{9}$ Preliminary results from the PostEboGui cohort of survivors in Guinea found that $15 \%$ met the threshold for psychological suffering on the Center for Epidemiologic Studies-Depression Scale, and $11 \%$ met the criteria for depression after a clinical consultation. ${ }^{11}$ These data are supported by qualitative research conducted among survivors from the 20142016 outbreak, which have reported feelings of sadness, depression, fear and anxiety. ${ }^{12} 13$

EVD was stigmatised both during and after the outbreak. ${ }^{152526}$ The intersection between disease-related stigma and mental health issues has been extensively studied, notably among HIV-positive populations. ${ }^{27} 28$ Davtyan et al explored similarities between EVD-related and HIV-related stigma and found that many of the same features of HIV-related stigma were shared with EVD-related stigma, such as the disease being perceived as divine retribution for immoral or improper acts. ${ }^{29}$ We found significant positive associations between 
Table 4 Univariable regression of PHQ-9 depression score

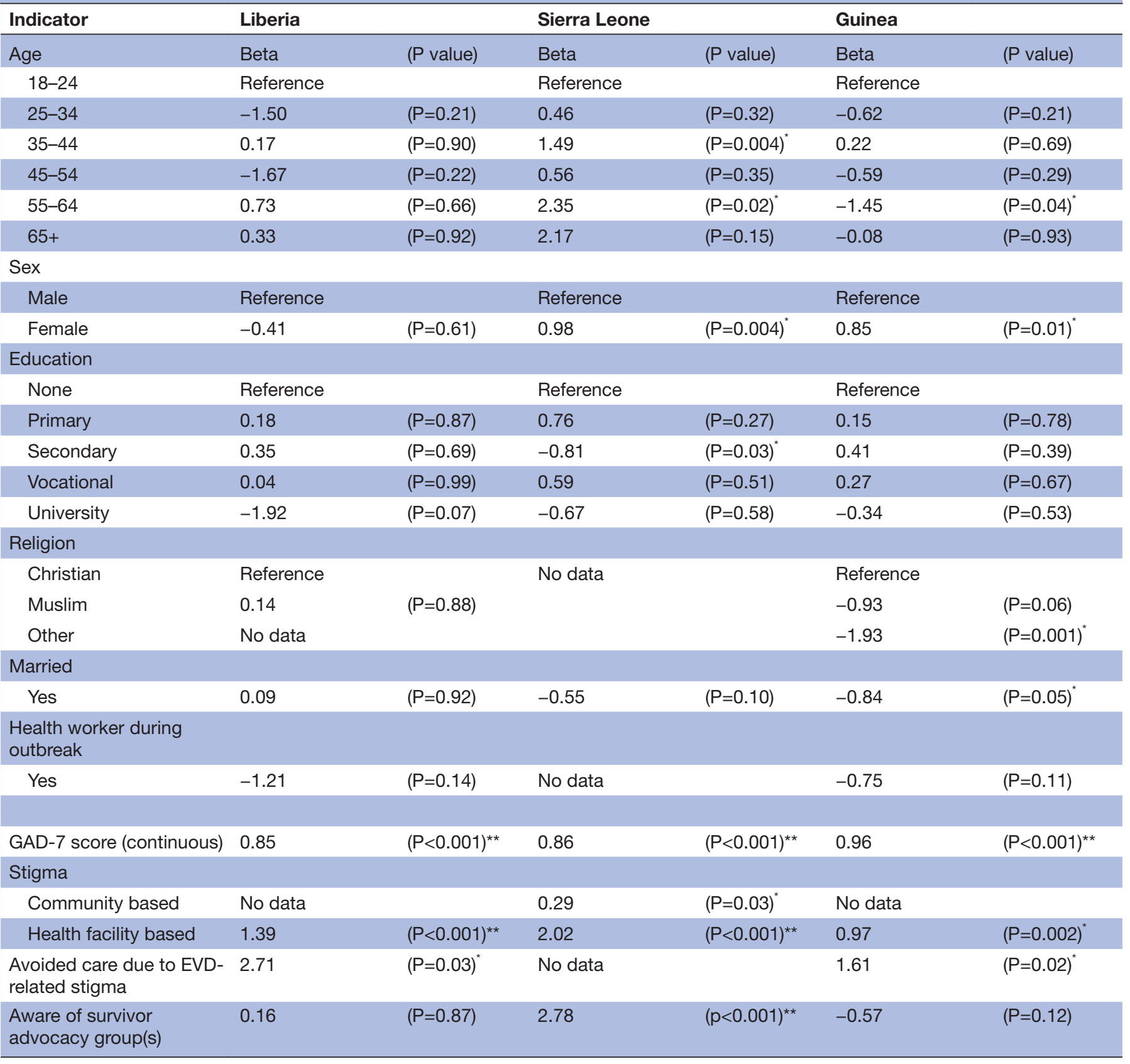

${ }^{*} \mathrm{P}<0.05,{ }^{*} \mathrm{P}<0.01$.

EVD, Ebola virus disease; GAD-7, Generalised Anxiety Disorder-7; PHQ-9, Patient Health Questionnaire-9.

depression and experiences of facility-based EVD-related stigma across all three countries. Relatedly, we found a significant association between depression and avoidance of care due to EVD-related stigma in Liberia and Guinea (equivalent data not collected in Sierra Leone), a concerning finding in the context of a population predisposed to mental health issues and in an environment with weak support and care structures.

Providing access to suitable mental health services to both EVD survivors and the general population is challenging for numerous reasons. Total mental health expenditure remains low, at an estimated USD $\$ 0.02$ per person in Liberia (data not reported for Sierra Leone and Guinea), and current health staffing is insufficient to meet needs, with an estimated $0.02-0.04$ psychiatrists and $0.33-$ 6.4 mental health nurses per 100000 people across the three countries. ${ }^{30}$ There is also insufficient infrastructure to provide specialised services such as psychiatric in-patient care, and stigma surrounding mental health conditions remains a barrier to both accessing and providing care. ${ }^{3132}$ However, efforts are being made to address these deficits. All three countries have official mental health policies which call for expanded resources for and access to mental health services and medications. ${ }^{30}$ To address 
Table 5 Univariable regression of GAD-7 depression score

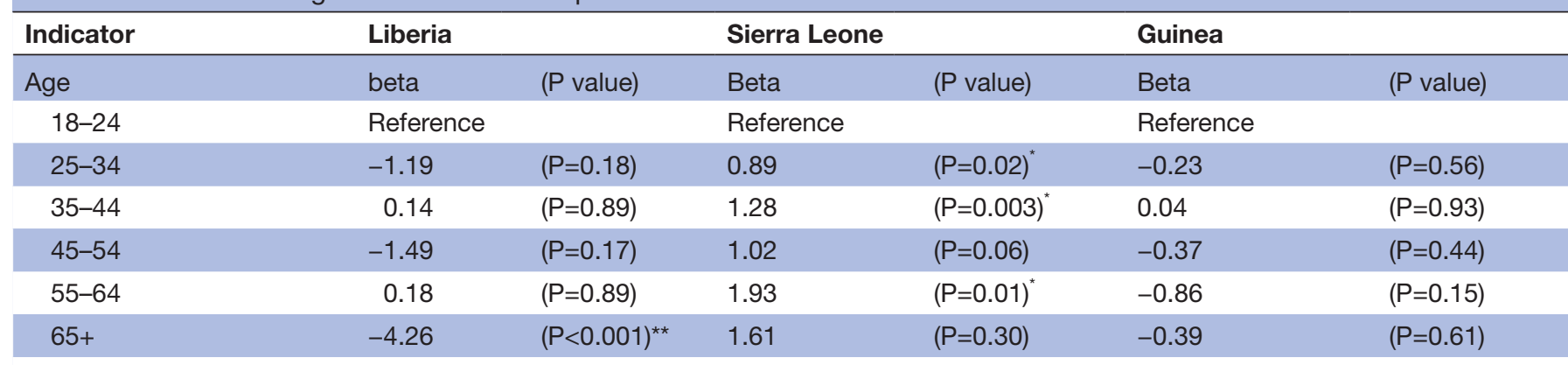

Sex

\begin{tabular}{|c|c|c|c|c|c|c|}
\hline Male & Reference & & Reference & & Reference & \\
\hline Female & 0.11 & $(P=0.86)$ & 0.79 & $(P=0.01)^{*}$ & 0.61 & $(P=0.03)^{*}$ \\
\hline \multicolumn{7}{|l|}{ Education } \\
\hline Primary & -0.23 & $(\mathrm{P}=0.77)$ & 0.53 & $(P=0.35)$ & 0.17 & $(P=0.69)$ \\
\hline Secondary & -0.10 & $(P=0.89)$ & -0.41 & $(P=0.18)$ & -0.05 & $(P=0.89)$ \\
\hline University & -2.10 & $(P=0.12)$ & 2.30 & $(P=0.13)$ & -0.22 & $(P=0.62)$ \\
\hline \multicolumn{7}{|l|}{ Religion } \\
\hline Christian & Reference & & No data & & Reference & \\
\hline Muslim & -0.38 & $(P=0.53)$ & & & -1.12 & $(P=0.003)^{*}$ \\
\hline Other & No data & & & & -1.18 & $(P=0.048)^{*}$ \\
\hline Yes & -1.76 & $(p=0.02)^{*}$ & No data & & -0.59 & $(P=0.18)$ \\
\hline PHQ-9 score (continuous) & 0.54 & $(P<0.001)^{\star *}$ & 0.65 & $(P<0.001)^{\star *}$ & 0.62 & $(P<0.001)^{\star *}$ \\
\hline \multicolumn{7}{|l|}{ Stigma } \\
\hline Community based & No data & & 0.48 & $(P<0.001)^{\star *}$ & No data & \\
\hline Health facility based & 0.54 & $(P=0.05)$ & 1.87 & $(P<0.001)^{\star *}$ & 0.38 & $(P=0.12)$ \\
\hline $\begin{array}{l}\text { Avoided care due to EVD- } \\
\text { related stigma }\end{array}$ & 1.60 & $(P=0.04)^{*}$ & No data & & 0.61 & $(P=0.27)$ \\
\hline $\begin{array}{l}\text { Aware of survivor advocacy } \\
\text { group(s) }\end{array}$ & -1.00 & $(P=0.37)$ & 2.10 & $(\mathrm{P}<0.001)^{\star \star}$ & -0.78 & $(P=0.007)^{*}$ \\
\hline
\end{tabular}

${ }^{*} \mathrm{P}<0.05,{ }^{* *} \mathrm{P}<0.01$.

EVD, Ebola virus disease; GAD-7, Generalised Anxiety Disorder-7; PHQ-9, Patient Health Questionnaire-9.

staffing shortages, programmes such as the WHO Mental Health Gap Action Program have been employed in all three countries to train clinicians, nurses, midwives and community health workers to provide basic mental health services in a variety of settings. ${ }^{31} 33$ While these measures are a step in the right direction, more work is necessary to make high-quality mental health services widely available for both EVD survivors and the general population.

\section{Limitations}

As this was a cross-sectional survey, no causal inferences between mental health and associated factors can be made. As an exploratory analysis, however, the data provide a better understanding of the prevalence and select correlates of both depression and anxiety among this understudied population.

Survivors were recruited from official, voluntary survivor registries. As a result, survivors in our sample may have lower internalised stigma, and since the registries are also used to validate access to survivor-specific medical care, may have higher engagement with care and support structures as compared with the general survivor population. However, thorough survivor mapping and engagement exercises were conducted as part of the ETP\&SS programme.

Due to the large sample population and limited resources, tentative diagnoses of depression and anxiety 
could not be validated through clinical consultations. The PHQ-9 and GAD-7 were chosen specifically because they are simple, thoroughly validated tools that have been used with a wide variety of populations, and data collectors were given ample training in their use.

Participants who chose not to complete all or part of the PHQ-9 and GAD-7 were excluded from relevant analyses. Those experiencing depression and anxiety may feel greater stigma and be less likely to choose to complete the questionnaires, resulting in an underestimation of these conditions within the study population. Data collectors received thorough training on describing the questionnaires (eg, reading a few sample questions) and process to participants, but participants were not pressured to complete the questionnaires against their will.

\section{CONCLUSIONS}

Our results indicate that depression and anxiety are common among EVD survivors in Liberia, Sierra Leone and Guinea, but that there is country-level heterogeneity in prevalence, severity and correlates of these conditions. All three countries should work to make mental health services available for survivors, and governments and organisations should consider the intersection between EVD-related stigma and mental health when designing programmes and training healthcare providers.

Acknowledgements The authors would like to thank USAID for funding the study and technical collaboration, central and regional Ministries of Health offices and survivor advocacy groups for their collaboration, in-country staff and data collectors for their unflagging efforts, and the survivor communities of Liberia, Guinea, and Sierra Leone for their support and participation.

Contributors All authors have participated sufficiently in the work to take responsibility for the content, including participation in the conception or design of the work, or the acquisition, analysis or interpretation of data and drafting the work. DA, ND, SA and JS contributed in the design of the work and data interpretation. RM, LS and MK oversaw country operations and data collection. SiS and SaS contributed to survey design and management of data collection. $\mathrm{KL}$ conducted the literature review. AS analysed the data, developed the structure of the article, and wrote the first draft. All authors reviewed and approved the final text.

Funding Research reported in this publication was funded through the Advancing Partners \& Communities (APC) Project, a cooperative agreement funded by the US Agency for International Development (Agreement No. AID-OAA-A-12-00047).

Disclaimer The content is solely the responsibility of the authors and does not represent the official views of USAID, JSI or the APC Project.

Competing interests None declared.

Patient and public involvement Patients and/or the public were involved in the design, or conduct, or reporting, or dissemination plans of this research. Refer to the Methods section for further details.

Patient consent for publication Not required.

Ethics approval Institutional review board approval was obtained from the John Snow. Review Board as well as by the ethical review committees of host country institutions: National Research Ethics Board of Liberia (approval NREB-BSR-014-18), Sierra Leone Ethics and Scientific Review Committee (approval on 09/27/2016), and Comité National d'Ethique pour la Recherche en Santé in Guinea (approval 042/CNERS/18).

Provenance and peer review Not commissioned; externally peer reviewed. Data availability statement Data are available on reasonable request.

Open access This is an open access article distributed in accordance with the Creative Commons Attribution Non Commercial (CC BY-NC 4.0) license, which permits others to distribute, remix, adapt, build upon this work non-commercially, and license their derivative works on different terms, provided the original work is properly cited, appropriate credit is given, any changes made indicated, and the use is non-commercial. See: http://creativecommons.org/licenses/by-nc/4.0/.

ORCID iD

Andrew Secor http://orcid.org/0000-0001-6882-6237

\section{REFERENCES}

1 PREVAIL III Study Group, Sneller MC, Reilly C, et al. A longitudinal study of Ebola sequelae in Liberia. N Engl J Med 2019;380:924-34.

2 World Health Organization. Interim guidance: clinical care for survivors of Ebola virus disease, 2016: 1-31.

3 Etard J-F, Sow MS, Leroy S, et al. Multidisciplinary assessment of post-Ebola sequelae in guinea (Postebogui): an observational cohort study. Lancet Infect Dis 2017;17:545-52.

4 Mattia JG, Vandy MJ, Chang JC, et al. Early clinical sequelae of Ebola virus disease in Sierra Leone: a cross-sectional study. Lancet Infect Dis 2016;16:331-8.

5 Wendo C. Caring for the survivors of Uganda's Ebola epidemic one year on. Lancet 2001;358:1350.

6 James PB, Wardle J, Steel A, et al. Post-Ebola psychosocial experiences and coping mechanisms among Ebola survivors: a systematic review. Trop Med Int Health 2019;24:671-91.

7 Vetter P, Kaiser L, Schibler M, et al. Sequelae of Ebola virus disease: the emergency within the emergency. Lancet Infect Dis 2016;16:e82-91.

8 Jalloh MF, Li W, Bunnell RE, et al. Impact of Ebola experiences and risk perceptions on mental health in Sierra Leone, July 2015. BMJ Glob Health 2018;3:e000471.

9 de St Maurice A, Ervin E, Orone R, et al. Care of Ebola survivors and factors associated with clinical Sequelae-Monrovia, Liberia. Open Forum Infect Dis 2018:5:1-8.

10 Hugo M, Declerck H, Fitzpatrick G, et al. Post-Traumatic stress reactions in Ebola virus disease survivors in Sierra Leone. Emerg Med 2015;05.

11 Keita MM, Taverne B, Sy Savané S, et al. Depressive symptoms among survivors of Ebola virus disease in Conakry (guinea): preliminary results of the PostEboGui cohort. BMC Psychiatry 2017;17:1-9.

12 Karafillakis E, Jalloh MF, Nuriddin A, et al. 'Once there is life, there is hope' Ebola survivors' experiences, behaviours and attitudes in Sierra Leone, 2015. BMJ Glob Health 2016;1:e000108.

13 Rabelo I, Lee V, Fallah MP, et al. Psychological distress among Ebola survivors discharged from an Ebola treatment unit in Monrovia, Liberia - a qualitative study. Front Public Health 2016;4:1-7.

14 Overholt L, Wohl DA, Fischer WA, et al. Stigma and Ebola survivorship in Liberia: results from a longitudinal cohort study. PLOS One 2018:13:e0206595-13

15 Calnan M, Gadsby EW, Kondé MK, et al. The response to and impact of the Ebola epidemic: towards an agenda for interdisciplinary research. Int J Health Policy Manag 2018;7:402-11.

16 Kroenke K, Spitzer RL. The PHQ-9: a new depression diagnostic and severity measure. Psychiatr Ann 2002;32:509-15.

17 Kroenke K, Spitzer RL, Williams JB. The PHQ-9: validity of a brief depression severity measure. J Gen Intern Med 2001;16:606-13.

18 Gelaye B, Williams MA, Lemma S, et al. Validity of the patient health Questionnaire-9 for depression screening and diagnosis in East Africa. Psychiatry Res 2013;210:653-61.

19 Cholera R, Gaynes BN, Pence BW, et al. Validity of the patient health Questionnaire-9 to screen for depression in a high-HIV burden primary healthcare clinic in Johannesburg, South Africa. J Affect Disord 2014;167:160-6.

20 Woldetensay YK, Belachew T, Tesfaye M, et al. Validation of the patient health questionnaire (PHQ-9) as a screening tool for depression in pregnant women: Afaan Oromo version. PLoS One 2018;13:e0191782-15.

21 Chibanda D, Verhey R, Gibson LJ, et al. Validation of screening tools for depression and anxiety disorders in a primary care population with high HIV prevalence in Zimbabwe. J Affect Disord 2016;198:50-5.

22 Spitzer RL, Kroenke K, Williams JBW, et al. A brief measure for assessing generalized anxiety disorder: the GAD-7. Arch Intern Med 2006;166:1092-7.

23 Whiteford HA, Ferrari AJ, Degenhardt L, et al. Global Burden of Mental, Neurological, and Substance Use Disorders: An Analysis from the Global Burden of Disease Study 2010. In: Mental, 
neurological, and substance use disorders: disease control priorities. 3 edn, 2016.

24 Baxter AJ, Vos T, Scott KM, et al. The regional distribution of anxiety disorders: implications for the global burden of disease study, 2010. Int J Methods Psychiatr Res 2014;23:422-38.

25 Nuriddin A, Jalloh MF, Meyer E, et al. Trust, fear, stigma and disruptions: community perceptions and experiences during periods of low but ongoing transmission of Ebola virus disease in Sierra Leone, 2015. BMJ Glob Health 2018;3:e000410-1.

26 Jalloh MF, Robinson SJ, Corker J, et al. Knowledge, Attitudes, and Practices Related to Ebola Virus Disease at the End of a National Epidemic - Guinea, August 2015. MMWR Morb Mortal Wkly Rep 2017;66:1109-15.

27 Amare T, Getinet W, Shumet S, et al. Prevalence and associated factors of depression among PLHIV in Ethiopia: systematic review and meta-analysis, 2017. AIDS Res Treat 2018;2018:1-9.
28 Jackson-Best F, Edwards N. Stigma and intersectionality: a systematic review of systematic reviews across HIV/AIDS, mental illness, and physical disability. BMC Public Health 2018;18:1-19.

29 Davtyan M, Brown B, Folayan MO. Addressing Ebola-related stigma: lessons learned from HIV/AIDS. Glob Health Action 2014;7:26058-4.

30 World Health Organization (WHO. Mental health atlas, 2017.

31 Gwaikolo WS, Kohrt BA, Cooper JL. Health system preparedness for integration of mental health services in rural Liberia. BMC Health Serv Res 2017;17:1-10.

32 Yoder - van den Brink HNC. Reflections on "building back better" child and adolescent mental health care in a low-resource postemergency setting: The case of sierra leone. Front Psychiatry 2019;10:1-15.

33 Faregh N, Lencucha R, Ventevogel P, et al. Considering culture, context and community in mhGAP implementation and training: challenges and recommendations from the field. Int $J$ Ment Health Syst 2019;13:1-13. 